\title{
Circulatory System's Diseases in the Elderly
}

Kourkouta Lambrini ${ }^{1}$, Papathanasiou V. Ioanna ${ }^{2}$, Koukourikos Konstantinos ${ }^{1}$, Kleisiaris Christos ${ }^{3}$, Fradelos C. Evangelos ${ }^{4}$ and Tsaloglidou Areti ${ }^{1}$

1. Department of Nursing, Alexander Technological Educational Institute of Thessaloniki, Thessaloniki, GR 57400, Greece

2. Nursing Department, Technological Educational Institute of Thessaly, Larissa, GR 41110, Greece

3. Nursing Department, Technological Educational Institute of Crete, Heraklion, GR 71500, Greece

4. 2nd Psychiatric Department, State Mental Hospital of Attica “Daphni”, Athens, GR 12462, Greece

\begin{abstract}
Old age is an important part of life as it concerns all human beings. It is well documented in the literature that various changes in the operation of specific organ systems happen and accompany the elderly. Moreover, with the age of a person, the cardiovascular system is altered and serious complications and diseases are caused leading a large number of older people until death. It is important that the health care professionals have substantial knowledge of the existing diseases in the elderly in order to be able to adequately address them as well as to defend and promote the health of older people.
\end{abstract}

Key words: Diseases, elderly, cardiovascular system, circulatory system.

\section{Introduction}

In Geriatrics, elderly are considered all the persons aged $>65$ years and they are divided into three groups: $65-75,75-85$ and $>85$ years. Today, it is estimated that $12.7 \%$ of the population is elderly. They are the fastest growing part of the population and by 2050, an increase of $147 \%$ in total and an increase of $389 \%$ of the population aged $>85$ years is expected worldwide [1].

Old age reflects the irreversible, progressive changes in morphology and function that are observed in cells, tissues, organs or throughout the body [2]. As the probability of a human to die increases with age, most of the changes that come with aging represent various discounts in the operational capacity of the organization [3]. Several studies have described the various changes in the operation of specific organ systems [4]. These changes are different in each organ system; the most common are the cardiovascular diseases, hypertension, diabetes, chronic sensory disorders, organic brain syndromes and accidents [5]. It is worth to note that the effects of the old age are not

Corresponding author: Kourkouta Lambrini, professor, research fields: history of nursing, ethics and deontology. only organic and physically evident but they have also psychological effects [6].

Furthermore, the cardiovascular system alters and many serious complications and diseases appear and are the leading cause of death to a large proportion of older people [7]. The main function of the organism's decay is the connective tissue degradation, which is equivalent to a loss of elasticity of all the tissues and organs. A feature easily visible to older persons is their total dyskinesia. The heart also follows the above mentioned loss of elasticity [8]. Cardiovascular disease is the main cause of death in Europe, leading to approximately 4.35 million deaths annually. A proportion of $49 \%$ of all deaths in Europe comes from CVD (cardiovascular diseases), 55\% of them are women and $43 \%$ men. Coronary heart disease accounts for about $50 \%$ and stroke for about $1 / 3$ of these deaths [9]. Moreover, according to the NSSG (National Statistical Service of Greece) 52,000 deaths (about $49 \%$ ) of a total of 105529 deaths in 2003 were due to cardiovascular diseases [10]. Although there is a significant decline from $30.8 \%$ of all deaths in 2000 to $28.1 \%$ in 2012 , the risk of cardiovascular disease in elderly remains a serious problem in the country [11]. 
The objective of this retrospective study is to identify the circulatory system's diseases of elderly people and their symptoms, as well as to examine the appropriate methods to prevent and treat them.

\section{Methods}

A review of the Greek and International literature on the subject was performed through the electronic databases Medline, Google Scholar, Scopus and the Association of Greek Academic Libraries Link (Heal-Link), using the following key words: cardiovascular diseases, circulatory system, old age, elderly. The described diseases are the most frequent and they have a significant impact on the quality of life of the elderly.

\section{Results and Discussion}

\subsection{Arterial Hypertension}

Hypertension is the permanent increase in blood pressure, namely when the systolic blood pressure is more than $140 \mathrm{~mm} \mathrm{Hg}$ or diastolic blood pressure more than $90 \mathrm{~mm} \mathrm{Hg}$ or both are increased simultaneously even at rest. Hypertension is very common in the elderly population, in both women and men. The determination of abnormal levels of blood pressure is desirable, since the mentioned risk can be reduced or eliminated by a therapeutic intervention [12].

In the hypertensive elderly, multiple pathophysiological changes occur that affect the progress of the disease and create particular problems in its therapeutic treatment. The observed changes in the elderly are: the low levels of renin, the increased sensitivity to sodium and increased peripheral vascular resistance due to loss of elasticity and due to extensive atherosclerotic lesions of the arterial walls [13].

The symptoms are dizziness, headache, ringing in the ears, blurred eyes, dyspnea and precordial pain during fatigue [14].

Changes in daily life of the elderly are necessary in treating hypertension; the proper diet, systematic exercise, reduced alcohol use, the smoking cessation and a reduction of cholesterol levels should be seriously taken into account by the patients. Medication is also important and necessary for the regulation of arterial hypertension. Equally important to the improvement of hypertension are various activities such as music therapy [15].

\subsection{Angina Pectoris}

Angina is an expression of coronary artery disease and it is characterized by slow duration crises of intense, caustic, spasmodic, substernal pain, which is caused by myocardial ischemia and it usually recurs [16].

Anginal pain may exist, without a substantial degree of heart disease, in conditions such as aortic stenosis. It can also occur in cases of anemia and hypoxemia, as well as in conditions of increased cardiac workload, in the beginning of intense exercise or intense tachycardia [17].

The ECG is the primary diagnostic method, although many patients with angina have a normal ECG at rest. The coronary angiography is a routine clinical method and causes minimal complications. Intensive diagnostic investigation is not recommended in the elderly, except of the cases where there is a difficulty in diagnosis or a planned coronary surgery [18].

\subsection{Myocardial Infarction}

Myocardial infarction is developed when a part of narrowed artery is completely occluded by a blood clot, resulting in stopping the supply of a heart's portion. The disease appears as a strong, unknown pain, which is reflected to the back of the sternum to the left and behind the shoulder and most of the times it comes without warning. [19]

Myocardial infarction has at least twice proportion of mortality in old age. The elderly are at a high risk but they are not the only ones who are affected; male population is at risk as well as women after menopause. Obesity, smoking, high cholesterol, blood pressure, sedentary lifestyle, heredity, diseases such as diabetes 
mellitus, and stress are the major causes leading to infarction [20, 21].

Acute myocardial in the elderly can be displayed as stroke or peripheral arterial embolism, dizziness, vomiting, abrupt feeling of weakness, unexpected diabetic coma or pulmonary embolism. This makes diagnosis difficult. The diagnosis of myocardial necrosis should be confirmed by the identification of specific enzymes [22].

In case of severe myocardial infarction the early arrival of the patient to hospital is of major importance as the main aim of the treatment is the start of thrombolytic therapy within 30 minutes and, if it is needed, the intra-coronary balloon placement within 90 minutes after the arrival [23].

\subsection{Cardiac Arrythmias}

By the term "arrhythmia" is meant every disorder of heart rhythm or heart rate, whether there is a decrease (bradycardia) or an increase (tachycardia) of it, beyond the normal range [24].

The causes of cardiac arrhythmias are many and some of them involve our everyday life, such as emotional stress, intense physical activity, alcohol or nicotine, intake of caffeine and medications [12]. Often, however, arrhythmia is caused by various diseases such as thyroid diseases, lung diseases, and disturbances in the collection of electrolytes (sodium, potassium) in blood as well as diseases such as gastroesophageal reflux disease, hiatal hernia, acute myocardial infarction, chronic myocardial ischaemia, heart disease and myocarditis [16].

In many cases, an arrhythmia may not be discernible by the patient. Sometimes though, it is perceived by chest pain, dyspnea, retrosternal pain, dizziness, unconsciousness and cardiac arrest [13].

Arrhythmia can be detected in time, if it happens during the performance of an electrocardiogram [17]. However, if the arrhythmia is transient and it is not displayed during the test, there are some other methods such as exercise test and 24-hour heart rhythm combined with a series of blood and urine tests that will help in a more accurate assessment of the person's health status and in discovering the possible out-cardiac causes of arrhythmias [24].

The treatments of cardiac arrhythmia vary, depending on the cause. They may not require any treatment except of some lifestyle changes. If this is not enough, then medication or/ and invasive methods such as the placement of artificial pacemaker are used [17, 24].

\subsection{Heart Failure}

Heart failure is the inability of the heart to supply the tissues of the body with the necessary amount of blood. Heart failure is a common and serious condition. This is a syndrome of all ages, it happens even in children, but it is more common in old age. There are no any observed differences between the two genders regarding the incidence of the disease, but there are some differences concerning its causes [25].

The causes leading to heart failure are: the narrowing of the arteries that supply blood to the heart, a previous myocardial infarction, the increased blood pressure, diseases of the heart valves, cardiomyopathies, congenital heart diseases, bacterial infections of the heart (endocarditis or myocarditis) hyperthyroidism and alcoholism [26,27].

The clinical picture of heart failure is shortness of breath, limitation of fatigue tolerance, and fluid retention that can lead to pulmonary congestion or peripheral edema [24].

The goal of heart failure's treatment is the relief of symptoms. The role of "non-madication" therapy is really important. Patients and relatives should be aware of issues about the proper diet, and especially regarding the use of salt and diuretics. Other measures such as limiting tobacco and alcohol have also a significant contribution to the treatment $[24,28]$

A major problem in the treatment of the disease in the elderly is the polypharmacy, which increases the chance of side effects with frequent orthostatic 
hypotension, bradyarrhythmias, toxic digitalis and electrolyte abnormalities [25, 29].

\section{Conclusion}

Old age is a part of life of particular importance as it concerns all the people. The increased morbidity of elderly people is nowadays a huge medical, social, and economic problem. The existing economic crisis worldwide is a serious fiscal problem that has an impact on health and insurance systems and in turn affects the proper treatment of the upcoming diseases in the elderly.

The changes in the cardiovascular system that occur in the elderly, are also affected by changes in other systems (especially kidneys - lungs), resulting in worsening of symptoms and prognosis and treatment difficulty. Comorbidity, polypharmacy and psychosocial disorders lead to the need of multidisciplinary approach of the elderly, while their participation in special rehabilitation programs is considered essential.

It is important for the health care professionals to have substantial knowledge in diseases with increased frequency such as those related to the circulatory system, in order to be able to treat them appropriately.

\section{References}

[1] Go, A. S., Mozaffarian, D., Roger, V. L., Benjamin, E. J., Berry, J. D., et al. 2012. "Heart Disease and Stroke Statistics-2013 Update: A Report from the American Heart Association. Dallas.” Circulation 127 (1): e6-e245.

[2] Malgarinou, M., Goulia, E., ed. 1991. The Nurse Near the Elderly. Athens: Beta. (in Greek)

[3] Plati, C., ed. 2008. Gerontological Nursing. Seventh Edition Revised. Athens: Papanikolaou A.B.E.E. SA. (in Greek)

[4] Theodosopoulou, E., and Raftopoulos, B. 2001. Morbidity and Mortality of the Elderly. Nursing 40 (2): 31-41. (in Greek)

[5] Iliadis, C., Monios, A., Frantzana, A., Taxtsoglou, K., and Kourkouta, L. 2015. "Diseases of Musculoskeletal System in the Elderly." Journal of Pharmacy and Pharmacology 3 (2): 58-62.

[6] Kourkouta, L., Iliadis, C., and Monios, A. 2015. "Psychosocial Issues in Elderly." Prog Health Sci. 5(1):
232-237.

[7] Babatsikou, F. 2010. "Epidemiological Data of Cardiovascular Disease in the Elderly." To Vima of Asclepius 9 (3): 230- 42. (in Greek)

[8] Babatsikou, F., ed. 2007. "Health Status and Determinants in the Elderly." Ph.D. thesis, The Kapodistrian University of Athens. (in Greek)

[9] British Heart Foundation, ed. 2010. Coronary Heart Disease Statistics. Accessed September 21, 2015. https://www.bhf.org.uk/research/heart-statistics.

[10] National Statistical Service of Greece (NSSG), ed. 2006. Statistical Physics of Motion of the Greek Population. Diachronikes Seires (2000-2005). Accessed October 10, 2015. https://www statistics.gr. (in Greek)

[11] Cancer and Cardiovascular Diseases. Accessed August 20, 2015. http://www.onmed.gr/ygeia-eidhseis/item/317964.

[12] Pagaltsos, A. ed. 2002. Pathology Data. Thessaloniki: M. Dimopoulou. (in Greek)

[13] Moisiadis, G., ed. 2004. Old Age Problems and Addressing Them. Thessaloniki: Graphic Arts. (in Greek)

[14] Pagaltsos, A., ed. 2004. Identification of Gerontology and Geriatrics. Thessaloniki: Publications Department TEI of Thessaloniki. (in Greek)

[15] Androulaki, Z., Kornelakis,E., and Koutedakis, K. 2003. "Homeschooling Nursing Monitoring of Chronically Ill Elderly." Nursing 42 (3): 364-73. (in Greek)

[16] Stefanadis, C., ed. 2005. Diseases of the Heart. Athens: Paschalidis. (in Greek)

[17] Chaniotis, F., Chaniotis, D., ed. 2002. Nosology-Pathology. Volume III. Athens: Litsa. (in Greek)

[18] Malami, D., Liberi, B. 2012. "The Treatment of Acute Coronary Syndromes Today in Southwestern Greece." Hospital Chronicles 7 (1): 20-5. (in Greek)

[19] Mallios, K. D. Coronary Heart Disease in Older Life. Accessed August 21, 2015. http://www.megamed.gr/wp-content/uploads/6344262595 58155059. (in Greek)

[20] Goldberg, R. J., Glatfelter, K., Burbank-Schmidt, E., Lessard, D., and Gore, J. M. 2006. "Trends inCommunity Mortality Due the Coronary Heart Disease." Amer. Heart J. 151: 501-7.

[21] Tahtsoglou, K., and Iliadis, C. 2015. "Obesity Causes." Scientific Chronicles 20(1): 54-63. (in Greek)

[22] Gergatos, G. 2001. "Clinical Manifestations of Acute Myocardial Infarction in Older Patients." Am. J. Geriatr. Cardiol. 10: 345-7.

[23] Ishakis, P. 2014. "Myocardial Infarction and Risk Factors." Perioperative Nursing 3 (3): 157- 66. (in Greek)

[24] Panoudaki-Brokalaki, I., ed. 2014. Diseases of the Heart and Nursing Care. Athens: Lagos. (in Greek)

[25] Antonakoudis, G. H., Poulimenos, L. E., Patestos D. P., 
Thireos, E., and Antonakoudis, H. G. 2011. "Heart Failure in the Elderly: Specific Clinical and Therapeutic Problems." Archives of Hellenic Medicine 28 (1): 33-8. (in Greek)

[26] Zile, M. R, Baicu, C. F, and Gaasch, W. H. 2004. "Diastolic Heart Failure-Abnormalities in Active Relaxation and Passive Stiffness of the Left Ventricle." $N$. Engl. J. Med. 350: 1953-9.

[27] Rich, M. W, and Kitzman, D. 2000. "Heart Failure in Octogenarians: A Fundamentally Different Disease." Am. J. Geriatr. Cardiol. 9 (Suppl): 97-104.

[28] McMurray, J. J, Ostergren, J., Swedberg, K., Granger, C.
B, Held P., Michelson, E. L., et al. 2003. "Effects of Candesartan in Patients with Heart Failure and Reduced Left-Ventricular Systolic Function Taking Angiotensin-Converting-Enzyme Inhibitors: The Charm Added Trial." Lancet 362: 767-71.

[29] Pitt, B., Poole-Wilson, P. A., Segal, R., Martinez, F. A., Dickstein, K., Camm, A. J., et al. 2000. "Effect of Losartan Compared with Captopril on Mortality in Patients with Symptomatic Heart Failure: Randomised Trial-The Losartan Heart Failure Survival Study Elite II.” Lancet $355: 1582-7$. 